\title{
Perception of bonding and occupational stress in a multidisciplinary cancer patients health team
}

\author{
Percepção de vínculo e estresse ocupacional de \\ equipe multiprofissional de saúde que atua no \\ cuidado de pacientes com câncer
}

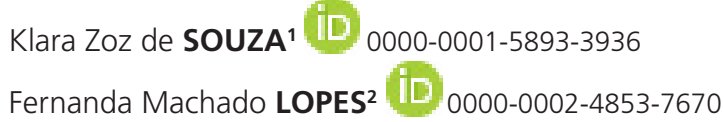

\begin{abstract}
Cancer is the second leading cause of death in Brazil and one of the positive features in the care of cancer patients is the professional-patient bond; however, due to the complexity of the disease, these professionals may develop occupational stress. This study investigated the perception of the bond and occupational stress of professionals who deal with cancer patients. Forty professionals from the surgical clinic and onco-hematology service at a hospital answered a questionnaire about bonding and stress at work. The results showed a greater perception frequency of the therapeutic bond, the same type identified as ideal. The onco-hematology team exhibited higher scores than the surgical clinic team in the perception of the bond and of the ideal therapeutic bond. The average occupational stress level of the participants was 2.08 (moderate), with no difference between the two teams. The power of health work models that use the bond between health professionals and cancer patients as a care technology stands out.
\end{abstract}

Keywords: Bonding; Cancer-patients; Health Care Services; Stress.

\section{Resumo}

O câncer é a segunda maior causa de óbitos no Brasil e um dos dispositivos que favorece o cuidado aos pacientes oncológicos é o vínculo profissional-paciente. No entanto, devido à complexidade da doença, os trabalhadores podem

\footnotetext{
$\nabla \nabla \nabla$

1 Universidade Federal de Santa Catarina, Centro de Filosofia e Ciências Humanas, Departamento de Psicologia. Florianópolis, SC, Brasil.

2 Universidade Federal de Santa Catarina, Centro de Filosofia e Ciências Humanas, Programa de Pós-Graduação em Psicologia. R. Engenheiro Agrônomo Andrey Cristian Ferreira, 240, Sala 10B, Carvoeira, 88036-020, Florianópolis, SC, Brasil. Correspondence to: F.M. LOPES. E-mail: <femlopes23@gmail.com>.

$\boldsymbol{\nabla} \nabla \mathbf{v}$

How to cite this article

Souza, K. Z., \& Lopes, F. M. (2022). Perception of bonding and occupational stress in a multidisciplinary cancer patients health team. Estudos de Psicologia (Campinas), 39, e200002. https://doi.org/10.1590/1982-0275202239e200002
} 
acabar desenvolvendo estresse ocupacional. Este estudo investigou a percepção de vínculo e o estresse ocupacional de profissionais que tratam de pacientes oncológicos. Quarenta profissionais de equipes de clínica cirúrgica e de oncohematologia de um hospital responderam a questionários sobre vínculo e estresse no trabalho. Os resultados mostraram maior frequência de percepção do vínculo terapêutico, mesmo tipo identificado como ideal. A equipe de onco-hematologia revelou escores mais altos do que a de clínica cirúrgica na percepção de vínculo e de vínculo ideal terapêutico. A média do nivel de estresse ocupacional dos participantes foi 2,08 (moderado), sem diferença entre as duas equipes. Destaca-se a potência dos modelos de trabalho em saúde que utilizam o vínculo entre profissional de saúde e pacientes oncológicos como tecnologia do cuidado.

Palavras-chave: Vínculo; Pacientes oncológicos; Serviço de Saúde; Estresse.

Brazil has undergone significant demographic and epidemiological profile changes due to the urbanization process and the advancement of health science and technologies. Changes in the population profile lead to changes in the morbidity and mortality profile, which, in turn, has a direct impact on national health policies. Chronic Non-Communicable Diseases (NCD), such as cardiovascular diseases, cancer, chronic respiratory diseases and diabetes mellitus, constitute the main population health problem, corresponding to $70 \%$ of the causes of death in the country (Ministério da Saúde, 2011). An appropriate approach to NCD includes action at the levels of promotion, disease prevention and comprehensive health care. Intersectoral actions are carried out through an organized network of services, with multiprofessional teams in the care lines and with the bond and responsibility of caregivers concerning the development of the autonomy of the health system users (Malta \& Merhy, 2010).

A study on the causes of illness and death at global levels conducted in 2017 revealed that malignancies were the second leading cause of death in the world (Roth et al., 2018). In Brazil, it is estimated that between 2018 and 2029, 600 thousand new cases of cancer will occur, with a profile similar to that of developed countries. The distribution of incidence by geographic region shows that the south and southeast regions concentrate $70 \%$ of the incidence, with the main types of cancers being prostate, female breast, lung and colon and rectum (Santos, 2018). Data from the Sistema Único de Saúde (SUS, Unified Health System) showed that neoplasms were the third leading cause of hospitalization in the country from 2002 to 2012 (Oliveira, Malta, Guauche, Moura, \& Silva, 2015). In this connection, data from the Oncology Observatory in 2016, directed by the Associação Brasileira de Leucemia e Linfoma (Brazilian Association of Leukemia and Lymphoma), suggest that deaths from neoplasms have been increasing at a faster rate than deaths from cardiovascular diseases and that they will be the main cause of deaths in Brazil from 2028-2029 (Matarazzo, 2016). Considering this projection, it is expected that oncology spending will also increase exponentially, so that cancer causes a major demand for investment in health policies at all levels (Ministério da Saúde, 2011).

Unified Health System was instituted by the Federal Constitution of 1988 and was consolidated through Laws 8,080 and 8,142, and constitutes the main mean of ensuring universal, comprehensive and equitable access to health. In the care of cancer patients, due to the different dimensions of the illness, different strategies for preventing and fighting cancer have been developed, among them stands out the National Humanization Policy (NHP) (Ministério da Saúde, 2009). Humanization involves valuing the different agents involved in the health production process. This happens through the encouragement of the subjects' autonomy and protagonism, collective participation in health practices and co-responsibility through solidary bonds between the different actors involved in the patient's care. Co-responsibility consists in the shared responsibility of the different players involved in the health production process, in order to establish commitment that favors health care. This policy also emphasizes that the bonding of people and families to the teams and longitudinal monitoring favor the creation of therapeutic bonds and the practice 2 of an expanded clinic (Ministério da Saúde, 2009). 
The creation of bonds by users is favored when they believe that the team is committed to their care and that it can contribute to their health, while on the side of the professional and the team, the basis of the bond is the commitment to the health of those who seek or are sought after by health services. The bond can be considered therapeutic when it generates autonomy, especially when ensuring care for the most vulnerable populations. Thus, there is a need to increase the response capacity of health services through the incorporation of simple yet resolutive technologies (Ministério da Saúde, 2009). For the link, it is necessary to have a regular source of care over time, which creates interpersonal ties, and that these ties can establish mutual cooperation among patients, families and health professionals so that patients can expose their anxieties and, subject to the professional's availability for listening and welcoming, it is possible to build solutions to the problems exposed (Barbosa \& Bosi, 2017). Dimensions of this bond include affection, help and respect, citizenship and patient participation during health care. There is a need to identify the health demands of SUS users and encourage them to achieve autonomy in their health-disease processes, through a perspective of co-responsibility, integrality and humanization, which, in turn, expands the effectiveness of health actions (Furlan, Santos, \& Marcon, 2017).

The bond is understood by several authors as a care technology (Feuerweker, 2014; Garcia, 2016; Malta \& Merhy, 2010). For Feuerweker (2014) there are three types of care technologies: hard, soft-hard and soft. Hard technologies are linked to diagnostic and therapeutic procedures and the knowledge required to feed clinical reasoning and also all other equipment and medicines used in therapeutic interventions. The soft-hard technologies are those that allow the health worker to look at the service user as an object of study and intervention, through well-defined scientific knowledge, such as the individual profession clinic and epidemiology, which call on the professional to balance out the hardness of a solid knowledge with the lightness of the patients' health intervention needs. Soft technologies are those that allow the production of relationships through the worker-user encounter through listening, interest and the construction of trust bonds. Thus, the bond functions as a soft technology to promote healthy living for individuals, families and the community, and is established from the moment that the professional is interested in the patient and recognizes his/her uniqueness and ways of living (Ilha, Dias, Backes, \& Backes, 2014). It is in this domain that the possibilities of the user's autonomy are expanded and the health-disease process is reframed.

The way in which each professional acts, by combining these three types of technologies, reflects the different conceptions of health and models of care. When the performance is focused only on hard or soft-hard technologies, the integral performance in health and humanization is impaired, and the subjects of these technologies, which are the patients, become reduced to procedures production units (Feuerweker, 2014) The dimension of care and soft technologies is fundamental to increase the capacity of health workers to deal with the subjectivity of the users' health needs (Malta \& Merhy, 2010). When health care is provided to cancer patients, the importance of soft technologies and bonding becomes even more evident, as cancer illness triggers organic and emotional reactions that cause ambiguous feelings, emotional imbalances and internal conflicts (Cano \& Moré, 2016). In providing care to this type of patient, health professionals should reflect on their practices and, often, change their position regarding life and death, pain and suffering of the other, since the way they face these issues has implications in patient care (Theobald, Santos, Andrade, \& De-Carli, 2016).

Understanding the perception of health workers about the bond with cancer patients' care can favor reflection on how the insertion of soft care technology takes place in the professional practice. Soft technologies can promote quality of life not only for the patient, but also for the health workers, who, when they better understand the users' demands, act in a more resolutive, assertive and safe way (Malta \& Merhy, 2010). On the other hand, health professionals who care for cancer patients are immersed in daily tensions, as a curative biomedical model, focusing hard technologies of care, frequent mutilations, losses and deaths, mourning of family members and complexity of treatments and interventions (Santos, Santos, Silva, \& Passos, 
2017). In this field, challenges occur daily for workers, who ask themselves how to deal with poor prognosis, with management of pain and symptoms, with terminality processes; and with the impossibility of a cure. These elements are surrounded by symbolic meanings and fantasies that permeate the performance of health professionals and make them more vulnerable to occupational stress, due to the context composed of specificities and highly complex assistance, management and organization.

Occupational stress can be defined as a set of manifestations from the work environment, which affect the worker's organism and have a potential which is harmful to their own health, involving aspects of organization, management, work conditions and the quality of interpersonal relationships at work (Ribeiro, Marziale, Martins, Galdino, \& Ribeiro, 2018). Health professionals start to perceive the demands of the professional environment as stressors when these demands exceed their coping capacity and end up generating negative reactions (Santos et al., 2017). Paschoal and Tamayo (2004) emphasize that there are several categories of stressors at work; among them, those related to interpersonal relationships in this environment, such as colleagues, manager and clients. If these interactions are conflicting and there is a discrepancy between situational demands and coping mechanisms, they generate emotional stressors, such as tension, irritability, nervousness, anger, job dissatisfaction, anxiety and depression.

Given the above and the scarcity of studies on health professionals and patients bonds, especially with regard to tertiary care and the high complexity of health services, this study aimed to investigate perception of the bond and the level of occupational stress of health professionals caring for cancer patients. Specifically, the investigation was intended to verify if there is a correlation between perception of the bond, type of bond and occupational stress and if there is a difference in these variables between the onco-hematology and surgical clinic teams in a general hospital. Given that the two phenomena impact the perspective of comprehensive care for cancer patients, studies that explore this relationship may provide information for interventions aimed at both the workers' health and the improvement of care for cancer patients in health services.

\section{Method}

\section{Participants}

The sample was non-probabilistic and selected for convenience. Professionals from the surgical clinic unit and the onco-hematology team of a public teaching hospital, who were working in these units/teams, maintaining weekly contact with cancer patients, were invited to participate in the survey. Approximately 160 professionals, including doctors, nurses, nursing technicians, nutritionists, psychologists, social workers, speech therapists, physiotherapists, pharmacists, dentists, second year medical school and multiprofessional residents who worked in these units/teams, with an average of 140 of them working in the surgical clinic unit and 20 in the onco-hematology team were convened. The complete onco-hematology team was composed of: doctors $(n=7)$, nurses $(n=4)$, nursing technicians $(n=2)$, psychologist $(n=1)$, pharmacist $(n=2)$, social worker $(n=1)$, nutritionist $(n=1)$, physiotherapist $(n=1)$ and dentist $(n=1)$. The sample was set up looking for a match by type of profession and was based on the maximum number of professionals working in the onco-hematology team $(n=20)$; therefore, the total sample was composed of 40 participants. As the surgical clinic team has 140 professionals, a draw was carried out when the number of participants per profession was greater than the number of the onco-hematology team (for example, 7 physicians were drawn out of 20 , to maintain the match type of profession between groups).

The inclusion criteria for participation in the study were: a) professionals who worked in the surgical clinic unit or onco-hematology team at the teaching hospital where the investigation was conducted and 
working weekly with cancer patients and who had been working in these units/teams for at least six months. Professionals who did not fully respond to the research scales and those who were away on vacation or for health reasons during the data collection period were excluded from the study.

\section{Instruments}

The instruments used were the Sociodemographic and Labor Profile Questionnaire; the Primary Care Assessment Tool (PCATool Brasil); the Professionals' Perception Questionnaire on the Bond with Cancer Patients; and the Stress Scale at Work, applied in this order and described below. The first was developed by the authors and was intended to investigate sociodemographic topics such as age, gender, and labor matters such as profession, time and sector of work, time working with cancer patients, time of graduation/ technical education, work regime and type of employment relationship.

The scale for evaluating the perception of health professionals about the longitudinal bond with the patient is the "longitudinality" session of the Primary Care Assessment Tool (PCATool), validated in Brazil as an Assessment Tool for primary health care (PCATool-Brasil) professionals' version (Ministério da Saúde, 2010). The "longitudinality" session has already been adapted and used alone to assess the existence of a continued source of attention, as well as its use over time, that is, the professional-user bond (Furlan et al., 2017). In the adapted version, the longitudinal bond with the patient is assessed using 13 items, on a 6-point Likert Scale, where zero represents the answer "I don't know" or "not applicable" and the score from one to five indicates the degree of preference or agreement with the statements (never $=1$, almost never $=2$, sometimes $=3$, almost always $=4$, always $=5$ ). The calculation of the scores was performed using the simple arithmetic mean of the response scores of the scale items for each participant, in order to subsequently, produce a total average score (Ministério da Saúde, 2010; Furlan et al., 2017; Hauser et al., 2013). The total average score of the bond was classified as unfavorable for average scores close to 1 and 2, as regular for scores close to 3, and as favorable for scores close to 4 and 5.

The Questionário de Percepção dos Profissionais sobre o Vínculo com Pacientes Oncológicos (QPPVPO, Professionals' Perception Questionnaire on the Bond with Oncological Patients) was developed by the authors based on their clinical experience in order to assess the perception of health professionals about the bond in their taking care of cancer patients at that hospital. As this questionnaire has not yet been validated, the PCATool-Brasil (previously described) was used at the same time as it is an instrument already validated in the Brazilian setting and is also indicated for use with health professionals. Through narrative literature review, a categorization of four types of bond was structured: Absence of bond (1), normative bond (2), therapeutic bond (3) and bond with diffuse boundaries (4) in which the professional initially identifies which category best represents his/her type of bond with cancer patients and then, which category he/she considers ideal for the care of these patients.

The Workplace Stress Scale (WSS) is an instrument for assessing occupational stress; it was developed and validated for use in Brazil, based on a review of the literature on psychosocial organizational stressors and on psychological reactions to occupational stress (Paschoal \& Tamayo, 2004). The scale showed satisfactory psychometric properties (alpha coefficient 0.85) and has already been used to assess occupational stress in palliative care assistance in oncology (Paschoal \& Tamayo, 2004; Santos et al., 2017). It consists of 23 items, with each item addressing a stressor and the corresponding reaction. Items are answered using a five-point agreement scale: 1 (strongly disagree), 2 (disagree), 3 (partially agree), 4 (agree) and 5 (strongly agree). The total score is the sum of the scores assigned to each item and divided by the total number of items on the scale, obtaining the arithmetic mean. From the mean, the study participants will be classified according to the intensity of stress. Bearing in mind that the scale offers five response options, with values ranging from 
one to five, the cutoff points adopted for the indication of stress were: low (1 to 2), moderate (2.01 to 4 ) or high (4.01 to 5).

\section{Procedures}

This study has been approved by the Human Research Ethics Committee of the Federal University of Santa Catarina to which it is affiliated (Protocol $n^{\circ} 3,296,514$ of January 1, 2019). The professionals were invited personally by the investigator (first author of this study) in their relevant units during working hours. The objectives of the survey were explained and the participants who agreed to participate signed the Free and Informed Consent Form and responded individually and in writing to the assessment instruments following the order in which they were presented in the Instruments section. The time used by the participants was about 10-15 minutes. Data collection was performed in a private room in the hospital, from July to August 2019.

\section{Data Analysis}

For data analysis, descriptive statistics were used, the Pearson correlation test and the T test for independent samples were used, since the data had a normal distribution (according to the KolmogorovSmirnov test; $p>0.05$ ). In all analyses, the significance level of $5 \%$ and the IBM ${ }^{\circledR S P S S}{ }^{\circledR}$ (version 21 ) were adopted.

\section{Results}

Most of the professionals in the teams surveyed were female (72.5\%), had a graduate degree (80.0\%), maintained daily contacts with cancer patients (70.0\%) and worked only in the hospital (62.5\%). Regarding the profession, most respondents were doctors (32.5\%), followed by nurses $(22.5 \%)$ and pharmacists (10.0\%). In terms of perceived bond, considering the 40 participants, the highest frequency was the type 3 bond, corresponding to the therapeutic bond (60.0\%), the same type identified as ideal by most professionals (85.0\%).

The means and Standard Deviation (SD) of the variables age, time after graduation, time of work in the hospital, time working with cancer patients, total week workload, PCATool Brasil - Professional version, WSS, the QPPVPO and the perception of ideal bond (QPPVPO) are presented together and separately by groups in Table 1. The significant levels of the mean difference between the two groups are also shown. It appears that there was no difference between the groups in the variables age, time after graduation, time working in the hospital, time working with cancer patients, level of work stress (WSS) (all with $p>0.05$ ).

However, the $T$ test for independent samples revealed a significant difference in the variable total week workload $(t(38)=2.27 ; p=0.02)$; the average of the total week workload of the surgical clinical team $(M=53.75$ was greater than that of the onco-hematology team $(M=41.10)$. Likewise, significant differences were found in the variables related to the perception of bond and ideal bond. In the questionnaire about bond perception, the mean of the onco-hematology team $(M=2.90)$ was higher than that of the surgical clinic $(M=2.50 ; t(38)=2.37 ; p=0.02)$; as well as in the item on ideal bond $(t(38)=2.69 ; p=0.01)$, in which the mean of the onco-hematology team $(M=3.05)$ was higher than that of the surgical clinic team $(M=2.75)$. A significant difference $(t(38)=3.41 ; p=0.002)$ was also found when the perception of bond was measured using the PCATool scale, with the mean of the onco-hematology team $(M=3.84)$ being higher than that of the surgical clinic (3.47). Therefore, in the measures related to the bond, all means were higher for the onco-hematology team in relation to the surgical clinic.

Correlation analyses of all variables revealed a moderate positive correlation between the two measures

6 of bond perception, the QPPVPO and the PCATool $(r=0.39 ; p=0.014)$, and between the QPPVPO and the 
Table 1

Descriptive mean and standard deviation analysis in general and by group and difference of the two groups mean analysis

\begin{tabular}{|c|c|c|c|c|}
\hline Variables & Group & $M$ & $S D$ & $p$ \\
\hline \multirow[t]{4}{*}{$\overline{\text { Age }}$} & Surgical Clinic Team & 36.05 & 9.97 & \\
\hline & Onco-hematology team & 40.45 & 6.60 & \\
\hline & All & 38.2 & 8.64 & \\
\hline & & & & 0.10 \\
\hline \multirow[t]{4}{*}{ After finishing school time (in years) } & Surgical Clinic Team & 11.30 & 9.99 & \\
\hline & Onco-hematology team & 16.65 & 7.25 & \\
\hline & All & 13.9 & 9.03 & \\
\hline & & & & 0.06 \\
\hline \multirow[t]{4}{*}{ Hospital working time (in years) } & Surgical Clinic Team & 7.10 & 9.31 & \\
\hline & Onco-hematology team & 11.65 & 8.59 & \\
\hline & All & 9.3 & 9.13 & \\
\hline & & & & 0.11 \\
\hline \multirow[t]{4}{*}{ Working time with cancer patients (in years) } & Surgical Clinic Team & 6.50 & 9.31 & \\
\hline & Onco-hematology team & 8.65 & 8.59 & \\
\hline & All & 7.3 & 8.36 & \\
\hline & & & & 0.40 \\
\hline \multirow[t]{4}{*}{ Total weekly workload } & Surgical Clinic Team & 53.75 & 21.82 & \\
\hline & Onco-hematology team & 41.10 & 12.43 & \\
\hline & All & 47.43 & 18.53 & \\
\hline & & & & *0.02 \\
\hline \multirow[t]{4}{*}{ PCATool Brasil - Professionals version } & Surgical Clinic Team & 3.47 & 0.32 & \\
\hline & Onco-hematology team & 3.84 & 0.36 & \\
\hline & All & 3.65 & 0.39 & \\
\hline & & & & *0.002 \\
\hline \multirow[t]{4}{*}{ Workplace Stress Scale } & Surgical Clinic Team & 2.02 & 0.65 & \\
\hline & Onco-hematology team & 2.15 & 0.47 & \\
\hline & All & 2.08 & 0.56 & \\
\hline & & & & 0.47 \\
\hline \multirow{4}{*}{$\begin{array}{l}\text { Professionals' Perception Questionnaire on the Bond } \\
\text { with Oncological Patients }\end{array}$} & Surgical Clinic Team & 2.50 & 0.60 & \\
\hline & Onco-hematology team & 2.90 & 0.44 & \\
\hline & All & 2.70 & 0.56 & \\
\hline & & & & ${ }^{*} 0.023$ \\
\hline \multirow[t]{4}{*}{ Ideal bond perception (QPPVPO) } & Surgical Clinic Team & 2.75 & 0.44 & \\
\hline & Onco-hematology team & 3.05 & 0.22 & \\
\hline & All & 2.90 & 0.38 & \\
\hline & & & & ${ }^{*} 0.010$ \\
\hline
\end{tabular}

Note: The Mean column presents the averages of the scores for each group and the sample as a whole assessed by each instrument. ${ }^{*} p<0.05$ showing the difference between groups. M: Mean; SD: Standard Deviation.

ideal bond perception questionnaire $(r=0.38 ; p=0.016)$. There was no correlation between the level of occupational stress (WSS), perceived bond and sociodemographic and labor variables (all with $p>0.05$ ).

Regarding the WSS, the analysis showed no significant difference between the scores of the two teams (surgical clinic $M=2.02$, onco-hematology $M=2.15 ; p=0.47$ ). The average level of occupational stress in the participants was 2.08, classified as moderate. According to the instrument used for this measurement, values from 1 to 2 indicate mild stress and from 2.01 to 4 indicate moderate stress.

\section{Discussion}

Regarding the bond, the analyses revealed a moderate positive correlation between the two measures of bond perception, and between the bond perception and the perception of the ideal bond. The highest 
frequency in self-perception was of the type corresponding to the therapeutic bond (60\%), described by the instrument through behaviors and attitudes such as "I know the family and social context of my patients and I usually advise patients and their families on the treatment and I answer their questions", "throughout the treatment, I perceive my patients becoming more independent", "I know the names of my patients and their families and treat them with affection", "sometimes I get emotionally involved due to my work, but this does not impact other aspects of my life (like social relationships outside work)", among others. In relation to the optimal bond, the therapeutic bond stands out and was also chosen by most professionals (85\%).

As already mentioned, bond development is a therapeutic resource and therapy is a fundamental part of the clinic in all health-related professions, as it studies and works with the most appropriate means to heal, rehabilitate, alleviate suffering and prevent potential damage to health (Garcia, 2016). In the therapeutic bond, the clear limits of the relationships established, both between the professional's personal life and his/ her performance, but also in relation to teamwork and case discussions in multiprofessional teams, fostering a more humane and full patient care (Barbosa \& Bosi, 2017; Garcia, 2016). These findings are related to the NHP (Ministério da Saúde, 2009), which produces changes in the form of care management for SUS users, by stimulating communication between the different players in the health and disease processes and fosters, through its guidelines, work practices that involve soft care technologies, such as embracing.

Some studies have investigated types of bonds of the health teams that work in different work models in the Basic Health Units (BHU), comparing units that work with and without the Family Health Strategy (FHS). The study by Martins, Abreu, Squevedo, and Bourget (2016) made that comparison using the PCATool and found that the teams that work on the health model built on the basis of the FHS, which advocates bonding as work and humanization technology, showed more positive bond perception than teams working in BHU in which the current health model is the traditional one. The aforementioned authors put forward as a hypothesis for explaining these results, the fact that the humanized health model, proposed by the NHP (Ministério da Saúde, 2009), by advocating closer contact with patients and team case discussion, provides care strategies with better performance and longitudinal care. On the other hand, in the studies of Frank, Viera, Ross, Obregón, and Toso (2015), which also compared different models of work in BHU (with and without FHS), positive results were found in relation to the bond in both models. These results were related to the regularity of care by the same health professional, and suggest the establishment of a strong bond with the $\mathrm{BHU}$ in question $(70.6 \%$ in the BHU with $\mathrm{FHS}$ and $68.2 \%$ in the BHU without FHS). In this study, the authors concluded that, regardless of the work model adopted in the BHU, when a positive bond is established in the unique relationship between the professional and the service user, there is an acknowledgment of the Units as a reference for care in relation to health needs.

Regarding the comparison between the two teams in this study, the surgical clinic showed an average weekly workload higher than that of the onco-hematology team. This difference can be explained due to the specific work model of the two teams: the surgical clinic team acts primarily in terms of outpatient diagnostic and preoperative assessments, hospitalizations for surgical procedures and outpatient follow-ups as long as the patient needs this monitoring. After evaluation, the patient is counter-referred to a specialized cancer monitoring service or to the primary health care network in his territory. In turn, the onco-hematology team works through the care line, which is a conduct line focused on the assistance flow to patients (and their families), centered on their range of needs, to ensure care using resources and inputs of different technological characteristics (Malta \& Merhy, 2010).

The work in a line of care model presumes a health care organization that has as a comprehensive care practices reference model, that responds to a concept of health beyond the treatment of diseases and that includes service users in a network of caring practices and in which a stand for life is taken. The line of care should aim to build responses to potential pain, anguish and afflictions, sufferings and problems that 8 reach health services. These answers do not only consist of procedures and doctors' visits, but they should 
also produce a feeling of care and autonomy in each user (Malta \& Merhy, 2010). According to the authors, in this work model the patient enters at any point in the service that gives the assistance (emergency services, outpatient clinics, hospitalization) and the interaction between the user and the health professional occurs

From the entry of the patient, there are a number of possibilities, from diagnostic and therapeutic support services, specialties, hospital care and others. The intervention must be carried out from prevention to health rehabilitation, by the same team (with the support of the others), until the demand that motivated the patient's search for the health service is fulfilled.

For Feuerweker (2014), these networks presuppose bonding, continuity and resolution and refer to the full care of the patient's health needs. The lines of care must be developed collectively and can help to increase accountability (of the team and the user) and better ensure their access. It is also noteworthy that, given the current epidemiological and demographic transition in the country and in the world, with the predominance of NCD and the growth of the elderly population, the demand for the aggregation of technologies and changing the performance model to a model that gives priority to the caregiving performance and the patients' autonomy (Malta \& Merhy, 2010).

For a better understanding about the bond in the framework of health, Gomes and Pinheiro (2005) also point out that the type of specific bonds among a set of people can be used to interpret the social behavior of the subjects involved, through social relationships. Thinking about how the social relationships between cancer patients and different teams' health professionals also involve understanding the social structure in which the relationship networks take place. Therefore, the difference between the two teams creates different possibilities of patient care, specifically of working models. Surgical clinic professionals more frequently work, in more than one workplace (another public institution, private institution or as a self-employed person) as compared to the onco-hematology professionals. It is suggested, as a hypothesis, that this difference is the result of the different intervention models between surgical clinic and medical clinic. The first one works with an investigation and diagnostic focused in surgical-oriented interventions, in which the patient usually remains in hospital for a short stay. Medical clinic interventions, on the other hand, usually require longer treatments, that demand monitoring for a longer period of time, at outpatient level. Thus, working in a surgical clinic makes it possible to operate in different settings, such as the possibility of working shifts in different hospitals.

Still comparing the teams, the average perception of the onco-hematology team bond was higher than that of the surgical clinic team in both bond measures; and the bond between onco-hematology professionals and cancer patients was perceived as being therapeutic, while the professionals of the surgical clinic were perceived as exhibiting an intermediary between the normative and the therapeutic bond. The normative bond (type 2) was described by the instrument through behaviors and attitudes as "due to the organization of my work, I have no time to answer patients' questions, but I am open to this dialogue, maintaining an empathetic posture", "during my work, I often think that I should learn more about patients' life stories", "at times when I'm overloaded at work, other professionals help me and provide care to my patients", "I deal with my patients and family members professionally, because I'm concerned that treating them in an affectionate way can overload me ", among others.

The term normative bond was used to describe the relationship between the health professional and the patient in which the professional has little time to answer questions of patients and their families, when there is a turnover of professionals over the case or when decision-making about the patient's treatment is unilateral and is not built together. Although there is an empathetic posture, there is little involvement between the parties, with a more on the spot monitoring of the patient's illness process, which may be the result of the professional's coping resources in the work context. The bond is addressed by Cano and Moré (2016) as a conduct of the doctor-patient relationship that can be characterized by professionals in a 
dichotomous way, as a promoting or hindrance factor to patient care. On the one hand, a more therapeutic bonding can favor the professional's practice by the empathy and affection bond, but, on the other hand, when characterized as normative, it can hinder the patient's access to the team or cause the professionals to suffer, when an emotional over-involvement between the team and the patient ensues.

The normative bond can also be understood as a relationship in which the user places responsibility on the health professional, in such a way that only the professional could solve the problems he/she faces since he/she is the holder of health knowledge. This is a continuous process and feedbacked between the parties (Garcia, 2016). Besides perceiving their bond as being more normative, surgical clinic professionals also perceive the ideal bond as being closer to type 2 bond (normative bond) as compared to onco-hematology healthcare professionals, who perceive the ideal bond closer to type 3 (therapeutic bond). Therefore, it is concluded that each team is providing care to cancer patients in a way that is consistent with their perception of the ideal bond. Based on the results, the onco-hematology team showed bonds considered favorable to the care provided to the patient, while the surgical clinic team displayed a bond considered regular for patient care. It should also be observed that the difference in perception of the bond in the two teams is not associated with the frequency of cancer patients' caregiving, as the two teams have close performance frequencies.

For Coelho and Jorge (2009), humanized health care is provided through the devices related to the technologies of relationships, and bonding is one of the main points of this process. The authors report that, as technological resources, access, welcoming and bonding promote more agile, welcoming and resolving health actions. The therapeutic bond as a soft technology in the relationship between the professional and the patient is based on the principle that professionals should be responsible for their patients, through an interaction that generates bonds. Silva Júnior and Mascarenhas (2008) emphasize that, in addition to being therapeutic, the bond must also be affective and continuous. The therapeutic dimension refers to the development of a feeling of trust in the care provided; the affective dimension highlights the professional's genuine interest in the patient's health issue, as a subject, to be able to consider him/her in his/her complexity; and the continuity of the therapeutic process is seen as strengthening the bond and the mutual feeling of trust between the professional and the patient.

Finally, the occupational stress variable was also analyzed in this study due to the high emotional load required when working with cancer patients. Literature data point to moderate to severe levels of stress on the part of the health teams working in different sectors of the hospital setting (Ferro \& Cavalcanti, 2015; Ribeiro et al., 2018). The study by Ribeiro et al. (2018) found that the majority of health workers in a hospital was exposed to intermediate and high levels of occupational stress due to the routine of the hospital environment which is marked by daily tension, high workloads, unhealthy working conditions and the need to maintain daily contacts with critically ill patients.

In the same direction, Ferro and Cavalcanti (2015) highlighted that the staff who works in hospital settings are exposed to the negative consequences of high stress activities, and almost half of the professionals evaluated by their study (47.5\%) were at high risk of developing illnesses associated to occupational stress. Such stress level was attributed to the peculiarities of this work context, which in addition to rigid institutional routines, also requires that the worker maintains a routine of daily contact with intense experiences of suffering and death.

The findings of this study are in line with the results found by other authors, since both groups exhibited a moderate level of stress, which may be the result of the homogeneity sought with the matching by profession in the two teams and with the similarity of working conditions, since the two teams worked in the same hospital, and thus, being immersed in the particularities of the organizational culture of the hospital investigated. Hospitals can be considered organizations configured based on social interactions, cultural, symbolic and imaginary systems, with their own value systems and norms that guide their members. In this 
connection, organizational culture is understood as sharing a reality in the institution, representing a collective identity (Rocha, Marziale, Carvalho, Cardeal, \& Campos, 2014; Vegro, Rocha, Camelo, \& Garcia, 2016).

\section{Conclusion}

Due to the scarce number of studies about the bond between health professionals and patients, especially with regard to tertiary care and the high complexity of health services, this study sought to verify a potential relationship between sociodemographic and labor variables, perception of bond and ideal bond and work stress of the professionals working in the hospital. The results showed a correlation between the variables related to the bond and a difference in this variable between the teams assessed, indicating the relevance of the bond as a soft technology for health care. However, the problems concerning the subject are not limited to this survey, as they are complex phenomena that deserve investigations using different designs.

A limitation of this study was the use of a self-report instrument, as this type of tool is susceptible to responses of social desirability. For future investigations of bonding and stress, the use of mixed measures is suggested; they should mix self-reports with observations or with biological measures such as skin conductance response or heart rate monitoring. It is also suggested to compare teams from different institutions and expand the survey to other teams, such as those of palliative care. In addition, mixed studies may be suggested that, through qualitative investigation, survey the perception of participants as well as investigations that compare the perception of bonding by the health team with the perception of patients.

When addressing the perspective of a more normative bond (or less favorable to comprehensive health care) between patients and the health team, no doubt obstacles in the development and implementation of SUS and its policies will be encountered, such as comprehensive care and universal access. However, there is a movement towards the reorganization of health services for soft and soft-hard technologies, such as the welcoming and the bond, for the advancement of SUS, in order to foster more consistent responses to the population's health problems and suffering, being careful that health care is not reduced to the biological body. Comprehensiveness seeks to recognize, in addition to the most explicit complaints, the patients' health demands and needs. Therefore, it is essential to acknowledge and reacknowledge the reality and uniqueness of each being, in order to establish the link as a health care technology.

From the findings on the differences in the perception of the teams' bonds assessed, new questions arise, such as: how can you promote favorable bonds for comprehensive health care, in line with SUS guidelines? What are the challenges for implementing the bond, as a soft technology of care? How do different work models and health frameworks shape the different teams' bonding perceptions? Further studies are still needed so that the answers to these questions can assist in the practice of Brazilian public health.

\section{Contributors}

K. Z. SOUZA contributed substantially to the writing of the Introduction, Method, Discussion and Conclusion sections. In addition, she participated in the development of data design and interpretation. F. M. LOPES contributed substantially to the conception and design of the study, analysis and interpretation of data, writing of the results section and review and approval of the final version of the article.

\section{References}

Barbosa, M. I. S., \& Bosi, M. L. M. (2017). Vínculo: um conceito problemático no campo da Saúde Coletiva. Physis Revista de Saúde Coletiva, 27(4), 1003-1022. http://dx.doi.org/10.1590/s0103-73312017000400008 
Cano, D. S., \& Moré, C. L. O. (2016). Estratégias de Enfrentamento Psicológico de Médicos Oncologistas Clínicos. Psicologia: Teoria e Pesquisa, 32(3). https://doi.org/10.1590/0102-3772e323211

Coelho, M. O., \& Jorge, M. S. B. (2009). Tecnologia das relações como dispositivo do atendimento humanizado na atenção básica à saúde na perspectiva do acesso, do acolhimento e do vínculo. Ciência \& Saúde Coletiva, 14(Suppl 1), 1523-1531. https://doi.org/10.1590/S1413-81232009000800026

Ferro, S. S. V., \& Cavalcanti, F. A. T. C. (2015). Estresse ocupacional e resiliência entre profissionais de saúde. Psicologia: Ciência e Profissão, 35(3), 900-915. https://doi.org/10.1590/1982-370300452014

Feuerweker, L. C. M. (2014). Micropolitica e saúde: produção do cuidado, gestão e formação. Porto Alegre: Rede UNIDA.

Frank, B. R. B., Viera, C. S., Ross, C., Obregón, P. L., \& Toso, B. R. G.O. (2015). Avaliação da longitudinalidade em unidades de Atenção Primária à Saúde. Saúde em Debate, 39(105), 400-410. https://doi.org/10.1590/0103-110420151050002008

Furlan, M. C. R., Santos, A. G., \& Marcon, S. S. (2017). O vínculo com o profissional de saúde no tratamento de tuberculose: percepção dos usuários. Revista de Enfermagem do Centro-Oeste Mineiro, 7, e1934. https://doi.org/10.19175/recom. v7i0.1934

Garcia, C. A. S., Jr. (2016). Cubanos e usuários do Sistema Único de Saúde: análise da produção de vínculos a partir do Programa "Mais Médicos" (Tese de Doutorado não-publicada). Universidade Federal de Santa Catarina, Florianópolis. https://repositorio.ufsc.br/xmlui/bitstream/handle/123456789/175798/345639.pdf?sequence=1\&isAllowed=y

Gomes, M. C. P. A., \& Pinheiro, R. (2005). Acolhimento e vínculo: práticas de integralidade na gestão do cuidado em saúde em grandes centros urbanos. Interface: Comunicação, Saúde, Educação, 9(17), 287-301. https://doi.org/10.1590/ S1414-32832005000200006

Hauser, L., Castro, R. C. L., Vigo, A., Trindade, T. G., Gonçalves, M. R., Stein A. T., ... Harzheim, E. (2013). Tradução, adaptação, validade e medidas de fidedignidade do Instrumento de Avaliação da Atenção Primária à Saúde (PCATool) no Brasil: versão profissionais de saúde. Revista Brasileira de Medicina de Família e Comunidade, 8(29), 244-255. https://doi.org/10.5712/rbmfc8(29)821

Ilha, S., Dias, M. V., Backes, D. S., \& Backes, M. T. S. (2014). Vínculo profissional-usuário em uma equipe da estratégia de saúde da família. Ciência, Cuidado e Saúde, 13(3), 556-562. https://doi.org/10.4025/cienccuidsaude.v13i3.19661

Malta, D. C., \& Merhy, E. E. (2010). O percurso da linha do cuidado sob a perspectiva das doenças crônicas não transmissíveis. Interface: Comunicação, Saúde, Educação, 14(34), 593-606. https://doi.org/10.1590/S1414-32832010005000010

Martins, J. S., Abreu, S. C. C., Squevedo, M. P., \& Bourget, M. M. M. (2016). Estudo comparativo entre unidades de saúde com e sem estratégia saúde da família por meio do PCATool. Revista Brasileira de Medicina de Família e Comunidade, 11(38), 1-13. https://doi.org/10.5712/rbmfc11(38)1252

Matarazzo, H. (2016). 2029: ano em que o câncer será a primeira causa de morte no brasil. São Paulo: Observatório de Oncologia.

Ministério da Saúde (Brasil). (2010). Manual do Instrumento de avaliação da atenção primária à saúde: primary care assessment tool pcatool - Brasil. Brasília: Autor. http://bvsms.saude.gov.br/bvs/publicacoes/manual_avaliacao_ atencao_primaria.pdf

Ministério da Saúde (Brasil). (2011). Plano de ações estratégicas para o enfrentamento das Doenças Crônicas Não Transmissiveis (DCNT) no Brasil 2011-2022. Brasília: Autor. http://bvsms.saude.gov.br/bvs/publicacoes/plano_acoes-_ enfrent_dcnt_2011.pdf

Ministério da Saúde (Brasil). (2009). Redes de produção de saúde (1a ed.). Brasília: Autor. http://bvsms.saude.gov.br/bvs/ publicacoes/redes_produca__saude_2009.pdf

Oliveira, M. M., Malta, D. C., Guauche, H., Moura, L., \& Silva, G. A. (2015) Estimativa de pessoas com diagnóstico de câncer no Brasil: dados da pesquisa nacional de saúde, 2013. Revista Brasileira de Epidemiologia, 18(Suppl 2), 146-157. https://doi.org/10.1590/19805497201500060013

Paschoal, T., \& Tamayo, Á. (2004). Validação da Escala de Estresse no Trabalho. Estudos de Psicologia, 9(1), 45-5. https:// doi.org/10.1590/S1413-294X2004000100006.

Ribeiro, R. P., Marziale, M. H. P., Martins, J. T., Galdino, M. J. Q., \& Ribeiro, P. H. V. (2018) Estresse ocupacional entre trabalhadores de saúde de um hospital universitário. Revista Gaúcha de Enfermagem, 39, e65127. https://doi. org/10.1590/1983-1447.2018.65127

Rocha, F. L. R., Marziale, M. H. P., Carvalho, M. C., Cardeal, S. F., \& Campos, M. C. T. (2014). A cultura organizacional de um hospital público brasileiro. Revista da Escola de Enfermagem da USP, 48(2), 308-314. https://doi.org/10.1590/ 
Roth, G. A., Abate, D., Abate, K. H., Abay, S. M., Abbafati, C., Abbasi, N., \& Abdollahpour, I. (2018). Global, regional, and national age-sex-specific mortality for 282 causes of death in 195 countries and territories, 1980-2017: a systematic analysis for the Global Burden of Disease Study 2017. Lancet, 392(10159), 1736-1788. https://doi.org/10.1016/ S0140-6736(18)32203-7

Santos, M. O. (2018). Estimativa 2018: incidência de câncer no Brasil. Revista Brasileira de Cancerologia, 64(1), 119-120. https://doi.org/10.32635/2176-9745.RBC.2018v64n1.115

Santos, N. A. R., Santos, J., Silva, V. R., \& Passos, J. P. (2017). Estresse ocupacional na assistência de cuidados paliativos em oncologia. Cogitare Enfermagem, 22(4), e50686. https://doi.org/10.5380/ce.v22i4.50686

Silva Júnior, A. G., \& Mascarenhas, M. M. (2008) Avaliação da atenção básica em saúde sob a ótica da integralidade: aspectos conceituais e metodológicos. In R. Pinheiro \& R. A. Mattos (Eds.), Cuidado: as fronteiras da integralidade. Rio de Janeiro: Abrasco.

Theobald, M. R., Santos, M. L. M., Andrade, S. M. O., \& De-Carli, A. D. (2016). Percepções do paciente oncológico sobre o cuidado. Physis: Revista de Saúde Coletiva, 26(4), 1249-1269. https://doi.org/10.1590/s0103-73312016000400010

Vegro, T. C., Rocha, F. R. L., Camelo, S. H. H., \& Garcia, A. B. (2016). Cultura organizacional de um hospital privado. Revista Gaúcha de Enfermagem, 37(2), e49776. https://doi.org/10.1590/1983-1447.2016.02.49776

Received: February 12, 2020

Final version: September 30, 2020

Approved: November 10, 2020 